\title{
Impact of a Breast Health Awareness Activity on the Knowledge Level of the Participants and its Association with Socio- Demographic Features
}

\author{
Samina Khokher ${ }^{1 *}$, Muhammad Usman Qureshi ${ }^{2 \&}$, Warda Fatima ${ }^{3}$, Saqib \\ Mahmood $^{4}$, Afaf Saleem ${ }^{5}$
}

\begin{abstract}
The developing countries have higher mortality rates for breast cancer. A reason for this is presentation at advanced stages due to low levels of public awareness. Activities are arranged by health authorities of developing countries to increase the knowledge of women but their effectiveness has not been evaluated in detail. A multiple choice questionnaire with questions about socio-demographic profile and questions about breast cancer knowledge was designed in local language Urdu, to evaluate the knowledge of the participants before and after an audio visual educational activity in Lahore, Pakistan. Scores of 0-2, 3-5 and 6-8 were ranked as poor, fair and good, respectively. Among 146 participants these scores were achieved by 1\%, 55\% and $45 \%$ before activity and $0 \%$, $16 \%$ and $84 \%$ after the activity. Overall $66 \%$ of participants increased their knowledge score. Younger age, higher education, reliance on television as source of information and being a housewife were associated with better impact of the awareness activity. For the six knowledge related questions $3 \%, 5 \%, 11 \%, 23 \%, 33 \%$ and 44\% more participants gave correct answers after the activity. However $6 \%$ and $7 \%$ fewer participants answered correctly for 2 questions related to the cause and the best prevention for breast cancer. The study indicated that awareness activities are effective to increase the knowledge of women and better impact is associated with higher education and younger age of women. The component analysis showed that the questions and related presentations using medical terms have a negative impact and should not therefore be used. Analysis of activity therefore leads to identification of deficiencies which can be remedied in future.
\end{abstract}

Keywords: Breast cancer - health education - awareness campaign - breast cancer prevention

Asian Pac J Cancer Prev, 16 (14), 5817-5822

\section{Introduction}

Breast Cancer is the most frequent cancer in the women worldwide (Jemal et al., 2011). The developing countries have lower incidence rates but higher mortality rates in the affected women. The higher mortality rates in these countries are attributed to the disease presentation at advanced stages and limited resources for the diagnosis and treatment (Moore et al., 2009). The main reasons for diagnosis at late stage are low levels of public awareness of breast health and lack of screening facilities (Aziz et al., 2004). The Breast Health Global Initiative (BHGI) developed in 2006, proposed breast health awareness as a means of early diagnosis in countries with limited resources (Anderson et al., 2006). Pakistan is a developing country with limited resources and has the highest incidence of breast cancer among the Asian countries, the ASR being 69.1 per 100,000 averaged over the years 1998 2002 (Bhurgri et al., 2006). Breast cancer in this region is characterized by aggressive disease affecting younger age women with late stage presentations (Naeem et al., 2008; Khokher et al., 2012). Awareness campaign through public health education has the potential of raising the knowledge and awareness level of the women for early detection of disease. The public health education generally relies on mass media and publication of articles in magazines and news papers. Talk shows on television or radio and outreach programs like lectures and seminars arranged for a group of people are also used to increase the awareness. Many lectures and seminars are being arranged by the local health authorities for increasing the knowledge level of women in Lahore, Pakistan. The effectiveness of these programs to achieve this objective remains unknown. There are many publications to assess the knowledge level of different groups of women and their attitude towards breast cancer, in the developing countries (Parsa et al., 2005; Parvez and Anwar 2005; Jaffary et al., 2005; Ahmed et al., 2006; Karayurt et al., 2008; Kumar et al.,

${ }^{1}$ Surgical Division, INMOL hospital, ${ }^{2}$ Nauman Associates, ${ }^{3}$ Department of Microbiology and Molecular Genetics, University of Punjab, ${ }^{4}$ Department of Human Genetics and Molecular Biology, University of Health Sciences, ${ }^{5}$ Central Park Medical College , Lahore, Pakistan*For correspondence:drsamkhokher@yahoo.com 
2009; Khokher et al., 2012; Radi 2013; Ranasinghe et al., 2013). There are few articles which report the impact of educational activities on the knowledge and practice of breast self examination (Yavari $\mathrm{P}$ and Pourhoseingholi MA., 2007; Gupta et al., 2009; Al-Shammari et al., 2012) and there is a report which assesses the impact of an awareness program on the knowledge level of women by comparing the population exposed to this program with the population not exposed to this program (Mena et al., 2013). However to the author's knowledge there is no published report from a developing country like Pakistan with low literacy rate, to assess the impact of any particular awareness activity on the knowledge level of these women. The present study evaluates the impact of an audio visual educational activity on the knowledge level of the participants and examines the socio demographic features associated with better impact of the activity among these women.

\section{Materials and Methods}

An awareness seminar for women was conducted by the Institute of Nuclear Medicine and Oncology Lahore in collaboration with a pharmaceutical company (SanofiAventis) on 13th February 2010 in Lahore, Pakistan. A multiple choice questionnaire was designed in local language, Urdu, to evaluate the knowledge level of the participants before and after the activity. The questionnaire was prepared in duplicate as a set of two papers stapled together and marked as $\mathrm{Xa}(\mathrm{X}=$ Serial number $)$ and $\mathrm{Xb}$. Xa was for the participant's profile information and the pre activity knowledge score while $\mathrm{Xb}$ was for the corresponding post activity knowledge score. Xa had three questions related to the socio-demographic profile of the participant followed by one question each on participant's own perception of her knowledge level and of mammography, source of her information and whether she has ever had BSE or CBE. Eight questions were formatted to assess their knowledge about basic breast cancer facts. Table 1 shows these knowledge related questions with the various answer options.

The questionnaire $\mathrm{Xb}$ had the eight questions related to their knowledge about basic breast cancer facts only. The questionnaires $\mathrm{Xa}$ and $\mathrm{Xb}$ were stapled together as sets. The participants were informed about the questionnaire and about the objective of the study. The questionnaires were distributed before the activity among those who agreed to participate, with instructions to fill in and hand over the Xa component before the educational activity. The $\mathrm{Xb}$ component was to be retained by the same participant (identified by the number of $\mathrm{X}$ ), for filling in and handing over after the educational activity. The educational activity comprised of three audio-visual presentations in the native language Urdu for the verbal component/lecture and power point slides for figures and description highlights in English. Three presentations lasting for about 20 minutes each were given. First by the radiologist on "Early detection of breast cancer: an overview", second by the surgeon on "Breast examination and surgical treatment of breast cancer" and third by the oncologist on "Treatment of breast cancer with drugs and radiation". The presentations were followed by the interactive, question and answer session. The filled $\mathrm{Xb}$ questionnaires were collected after the lectures before the session closed.

The data was entered and analyzed by SPSS version 14. Each correct answer of knowledge related question was scored as one and incorrect as zero. Any question not attempted was also scored as zero. For the description of knowledge level of participants, the score was summed up as the knowledge score achieved by each participant before and after the activity. Knowledge score of zero, one and two was ranked as "Poor", three, four and five as

Table 1. Questionnaire with Questions about Breast Cancer Related Knowledge and the Answer Options

\begin{tabular}{|c|c|}
\hline Questions & Answer Options \\
\hline 1.What is mammography? & $\begin{array}{l}\text { A.An X-ray of breast } \\
\text { B.Examination by a doctor } \\
\text { C.Some type of cancer treatment }\end{array}$ \\
\hline 2.Is mammography harmful for the woman exposed to it? & $\begin{array}{l}\text { A.Yes } \\
\text { B.No }\end{array}$ \\
\hline 3.What is the approximate life time risk of breast cancer? & $\begin{array}{l}\text { A. } 1 \text { in } 10 \\
\text { B. } 1 \text { in } 100 \\
\text { C. } 1 \text { in } 1000\end{array}$ \\
\hline 4.What is the cause of breast cancer? & $\begin{array}{l}\text { A.Unknown } \\
\text { B.Due to some surgery/medicine } \\
\text { C.Due to contact with any patient of breast cancer }\end{array}$ \\
\hline 5.What are the symptoms of breast cancer? & $\begin{array}{l}\text { A.Any lump or change in shape } \\
\text { B.Any new feeling or pain } \\
\text { C.Any recent change or new development } \\
\text { D.Any of the above }\end{array}$ \\
\hline 6.What is the most important risk factor for developing breast cancer? & $\begin{array}{l}\text { A.Who has recurrent pain in the breast } \\
\text { B.Who has not breast fed her children } \\
\text { C.Who has a positive family history for breast cancer }\end{array}$ \\
\hline 7.What is the best strategy for prevention of breast cancer? & $\begin{array}{l}\text { A.Some special medicine/diet } \\
\text { B.Breast feeding } \\
\text { C.Screening for early diagnosis and Treatment }\end{array}$ \\
\hline 8.When does treatment provide maximum chance for cure? & $\begin{array}{l}\text { A.After diagnosis at early stage } \\
\text { B.After diagnosis at any stage }\end{array}$ \\
\hline
\end{tabular}


Impact of a Breast Health Awareness Activity on Knowledge Level and its Association with Socio-Demographic Features

"Fair" and six, seven and eight as "Good". For association of knowledge gain with the socio-demographic features, the pre activity and post activity knowledge scores were compared on a two point scale of; no change/decrease in knowledge score versus increase in knowledge score. The participants with correct answers to 8 knowledge related questions and pre activity and post activity knowledge scores were compared by descriptive statistics.

\section{Results}

The sets of printed questionnaires were distributed among 168 participants. Total of 318 single questionnaires were received back. 159 of them were Xa and 159 were $\mathrm{Xb}$. When arranged as set of $\mathrm{Xa}$ and $\mathrm{Xb}, 151$ sets were complete while 16 had missing "a" or " $b$ " component of the questionnaire. Majority of the participants $(80.4 \%)$ were below 30 years of age, with education between $10-14$ years $(56.5 \%)$ and majority of them $(73.5 \%)$ were students. $15 \%$ participants were $31-50$ years old and only $2 \%$ were more than 50 years old. Among the students $36 \%$ were medical or allied health sciences students. $72 \%$ of the participants considered themselves knowledgeable about breast cancer while $25 \%$ had self perception of being deficient on the subject. Education was the most common source of information about breast cancer $(58.4 \%$ of participants) in the study group followed by Television (17\%). About equal number of participants did (46\%) or did not (52\%) practice Breast Self Examination (BSE). Vast majority $(85 \%)$ of the women had never undergone Clinical Breast Examination (CBE).

Figure 1 shows the percentage of participants giving correct answer to individual breast cancer knowledge related question, in the pre-activity (Before) and postactivity (After) phase. The percentage of participants with correct answers increased for all questions except for two questions (Q 4 and Q 7). For three questions (Q 3, 5 and 8) a larger proportion of participants gave correct answers after the activity as compared with before the activity. For these questions $47 \%, 33 \%$ and $23 \%$ more participants respectively, answered correctly after the activity, while only a small proportion of participants improved on Q 1 , 2 and $6(5 \%, 11 \%$ and $3 \%$ respectively). The proportion of participants with correct answers of Q4 and Q7 decreased after the activity as $44 \%$ of participants answered Q4 correctly before the activity compared to $37 \%$ after the activity (difference of $7 \%$ ) and $91 \%$ of participants

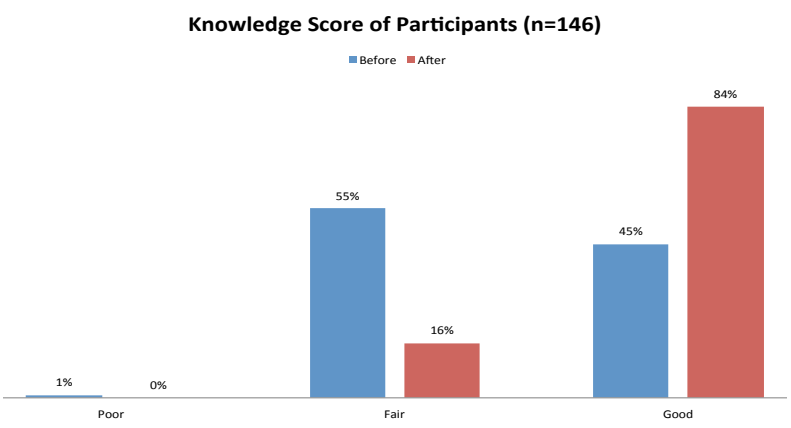

Figure 1. Knowledge Score of Participants before and After the Activity answered Q7 correctly before the activity compared to $85 \%$ (difference of $6 \%$ ) after the activity.

Five participants did not answer some questions related to their socio-demographic features and therefore after excluding them, data of 146 participants was available for further analysis of association of knowledge gain with their socio-demographic features. Figure 2 shows the pre-activity and post-activity knowledge scores of these participants on a scale of three; "poor", "fair" and "good". Before the activity, $1 \%$ of the participants had poor, $55 \%$ had fair and $45 \%$ had good knowledge score, while it was $0 \%, 16 \%$ and $84 \%$ respectively after the activity. Table2 shows the gain in knowledge score of these participants in relation with their socio-demographic features on a scale of; no change/decrease in knowledge score or increase in knowledge score. $66 \%$ of the participants increased their knowledge scores while $34 \%$ showed decrease or no change in their knowledge score. High proportion of women who improved their knowledge scores were with young age ( $<20$ years), Medium and high level of education (From Matric to Graduation and more than graduation), housewives with no specific profession

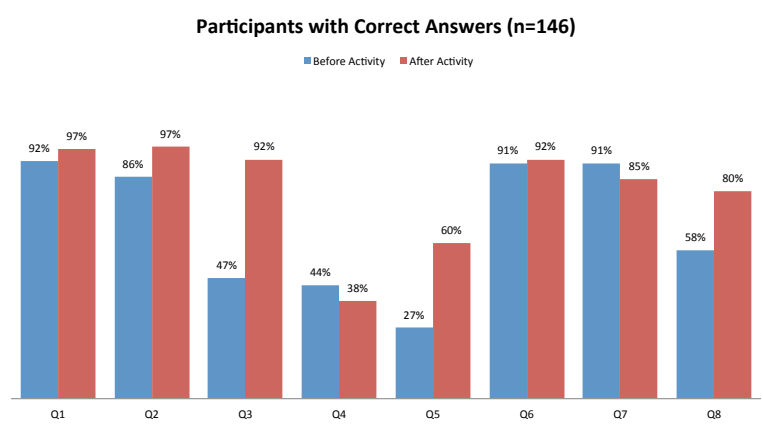

Figure 2. Proportion of Participants with Correct Answers to Breast Cancer Knowledge Related Questions

Table 2. Change in the Knowledge Score of Participants in Relation to their Socio-Demographic Features

\begin{tabular}{lccc}
\hline Parameter & $\begin{array}{c}\text { Number of } \\
\text { Participants }\end{array}$ & $\begin{array}{c}\text { Decreased or } \\
\text { Same Score }\end{array}$ & $\begin{array}{c}\text { Increased } \\
\text { Score }\end{array}$ \\
\hline Age & & & \\
$\quad<20$ yrs & 57 & $28 \%$ & $72 \%$ \\
20- 30 yrs & 64 & $38 \%$ & $63 \%$ \\
$>30$ & 25 & $36 \%$ & $64 \%$ \\
Education & & & \\
Less than Matric & 11 & $45 \%$ & $55 \%$ \\
Matric to Graduation & 76 & $32 \%$ & $68 \%$ \\
$\quad$ More than graduation & 59 & $34 \%$ & $66 \%$ \\
Profession & & & \\
$\quad$ House wife & 21 & $19 \%$ & $81 \%$ \\
Job & 14 & $50 \%$ & $50 \%$ \\
Medical & 56 & $38 \%$ & $63 \%$ \\
$\quad$ Student & 55 & $31 \%$ & $69 \%$ \\
Source of information & & & \\
Internet & 2 & $50 \%$ & $50 \%$ \\
Magazines & 9 & $44 \%$ & $56 \%$ \\
Relatives/Hearsay & 19 & $47 \%$ & $53 \%$ \\
Television & 27 & $22 \%$ & $78 \%$ \\
Through education & 89 & $33 \%$ & $67 \%$ \\
Grand Total & 146 & $34 \%$ & $66 \%$ \\
\hline
\end{tabular}


and those who relied on Television as their source of information.

\section{Discussion}

The knowledge of breast cancer symptoms and practice of breast self examination is inadequate among women living in the developing countries (Ahmed et al., 2006; Karayurt et al., 2008; Kumar et al., 2009; Khokher et al., 2012; Radi 2013; Ranasinghe et al., 2013). However there is evidence of significant improvement with the educational and awareness activities (Gupta et al., 2009). The most efficient way of creating awareness and increasing the knowledge level of the women about breast cancer is not known. In the field of health education different approaches are used. It is assumed that they all raise the level of knowledge but the impact of these activities is likely to vary with the type of activity, education level as well as the socio cultural background and mind set of the participants. Public cancer awareness campaigns have been associated with some improvement in awareness and early diagnosis of cancer but their impact and long term benefits are not clear. A systematic review has shown that there is only limited evidence that they increase the cancer awareness of communities (Austoker et al 2009). Concerns have been raised about the misleading presentations in the popular magazines regarding breast cancer (Burke et al., 2001) and of using them for commercial gains. Mass awareness activities including national campaigns, participation in exhibitions, events and mass media (magazines, newspapers, etc.) have been used at random according to the resources or the convenience of the conducting body and the cultural background of the specific region but the impact in general has never been evaluated or quantified. The interpersonal and outreach activities for public health awareness like an interactive lecture and small scale seminar of the present study, provides the opportunity of assessment of their effectiveness in the same setting. This may help in planning better and more effective awareness activities in future. In order to succeed, the breast cancer awareness programs should be structured and tailored to fit individual communities (AbdelHadi 2006). To the authors knowledge there is no published study which assesses the effectiveness of awareness activities aimed at raising the knowledge level of the women about breast cancer in Pakistan. The present study is an attempt to evaluate and quantify the rise in the knowledge level of participants after a small scale health awareness activity. This study was conducted during one of a series of these awareness activities conducted in Lahore, Pakistan.

Improvement in the knowledge scores of the participants in the present study was better among younger age group in the teenagers among whom $72 \%$ showed increase in their knowledge scores compared with $64 \%$ of the older age group of participants. This is in consistence with the fact that young mind is the most receptive and impressionable. Studies report variable association of breast cancer related knowledge among women of different age groups. It has been reported from a primary health care setting that older women had poorer breast cancer related knowledge as compared to younger women (Dolen et al 1997) while a recent study conducted on general women population in Kuwait shows that older women ( $>50$ years) are more knowledgeable about breast cancer related facts (Saeed et al 2014). To the authors knowledge there is no reported study to find association of age with the improvement in knowledge score after the awareness activity. The present study however has the limitation of lack of adequate representation of older age women among the study participants, as only $2 \%$ of participants were more than 50 years and only $15 \%$ were more than 30 years of age.

Higher education and literacy has been associated with better knowledge and awareness of breast cancer issues (Somdatta and Baridalyne., 2008; Khokher et al., 2011; Gürdal et al., 2012; Harirchi et al., 2012; Sathian et al., 2014). A significant proportion of the participants in the present study were educated and their knowledge score prior to the activity was better than the score reported from the university students of Al-Mukalla city in Yemen. The participants of present study had $1 \%, 55 \%$ and $45 \%$ poor, fair and good knowledge score respectively as compared to $59 \%, 40 \%$ and $1.4 \%$ from Yemen (Ahmed 2010) and a previous report from educational institutions from Lahore, Pakistan of $14 \%, 59 \%$ and $27 \%$ respectively on a three point scale (Khokher et al., 2011). The pre-activity Knowledge score of participants in the present study was also more than that of university students of Malaysia reported on a five point scale as $10.8 \%, 20.4 \%, 50 \%, 18 \%$ and $0.8 \%$ scores ranging from "Very poor" to "Very good" (Hadi et al., 2010). In our study the educated groups were benefitted more by the activity to raise their knowledge score as compared to the low education group (Less than Matric). It is possible that some basic education is required to get the desired knowledge gain from an activity which is relying on many words of English as well as power point slides in English. It is therefore inferred that to increase the awareness of low education group of population, the presentations as well as lectures should all be in the local language understood by them.

Mass media campaigns have been shown to produce positive changes in the health related behavior across large populations (Wakefield et al., 2010). Majority of women participants of the reported studies from developing countries narrate television as their main source of information (Khokher et al., 2011). The present study has shown that the group of participants relying on Television as their source of information was the most benefitted and the group of participants relying on relatives or hearsay, benefitted least from the educational activity and the audio visual presentations. Talk shows and documentaries on television are an effective source of information for the general public. Studies have shown higher health awareness and knowledge of people using television as their source of information (Khokher et al., 2011; Khakbazan et al., 2014). Many women with lower literacy in the developing countries however still rely on relatives and general hearsay for health issues. They are reluctant to consult male health care professionals for breast related problems (Hussain and Ansari., 1996) and their negative socio-cultural perception about breast cancer along with 
Impact of a Breast Health Awareness Activity on Knowledge Level and its Association with Socio-Demographic Features

their belief in traditional medicine is the main reason for delay in presentation (Odusanya and Tayo., 2001). They prefer to rely on interpersonal exchange of experiences and knowledge rather than medical advice. These women have many misconceptions and wrong beliefs which are communicated to others without any verification or evidence. Television as the source of information was used by $17 \%$ of the study participants compared with $12.5 \%$, relying on the relatives or the hearsay. The 12.5 $\%$ participants of the present study, relying on the relatives or the hearsay derived little benefit from the audio-visual educational activity presented to them as $47 \%$ of them did not improve their knowledge score.

The present study showed significant overall improvement in the knowledge score of participants after the audio visual presentations as $66 \%$ of the participants improved their knowledge score. When the data was analyzed for each question individually level of improvement varied for different questions. Maximum improvement was observed in Q 3. However for Q4 and Q7 a larger proportion of participants answered wrongly after the activity (44\% of participants answered Q4 correctly before the activity compared to $37 \%$ after the activity and $91 \%$ of participants answered Q7 correctly before the activity compared to $85 \%$ after the activity). This was unexpected and unintended. The related presentation and the construction of the question were therefore reviewed.

When the questions Q4 and Q7 were critically reassessed it was observed that Question 4 was constructed to assess the knowledge of participants about the myths and taboos related to cause of breast cancer and the correct answer was that exact cause still remains unknown. Question 7 was constructed to assess the knowledge of participants about the best strategy for prevention of breast cancer with three answer options ( some special medicine/diet, breast feeding, screening for early diagnosis and treatment) to lay emphasis on screening for early diagnosis and treatment (Secondary prevention) as primary prevention is not possible. The presentations were reviewed and it was realized that no information was provided about the possible causes of breast cancer, rather many "Risk factors" were described in the presentations without giving the audience any concept of the difference between Causative factor and a Risk factor. It is therefore presumed that the message was not clear and the narrated Risk factors were perceived as Causative factors by some participants. It is inferred that the general public cannot understand the medical terminology of risk factor and the difference between a Causative factor and a Risk factor should be more clearly described. Similarly the strategy of Secondary prevention by early diagnosis and treatment at an early stage is a concept of community medicine. For a nonmedical person the word "Prevention" is synonymous with "Primary prevention" which is simple to understand as a preventive strategy where disease is prevented before its occurrence. The levels of disease prevention as used in public health policy were not described and secondary prevention by early diagnosis was not clearly phrased as a preventive strategy. It is therefore inferred that the women in general public cannot understand the medical terminology of various levels of prevention of disease as applied in public health, which should therefore be more clearly described. The Q7 was in a way linked to Q4 as common sense implies that if one knows some specific cause of breast cancer like some food or medicine, one can prevent breast cancer by refraining from the use of that food or medicine. Although the awareness presentations were prepared in local language "Urdu" but the concepts of "Risk" factor versus causative factor and early diagnosis as the preventive strategy, were inadequately translated and explained which resulted in decreased knowledge of participants on these two questions. This raises the need of prior definition of the targets of educational activities to raise public awareness and later critical analysis of all components of the activity. In case of failure to achieve targets as a whole or in part, studies are required to look for the causes of unintended results so that they can be remedied in future activities.

In conclusion, The breast cancer related knowledge is inadequate among women living in the developing countries. Knowledge and thereby breast cancer awareness is raised by audiovisual educational activities and the impact is higher in educated women of younger age groups relying on Television/ media for mass communication rather than uneducated women relying on hearsay as a source of information. The use of medical terms should either be avoided in these talks or they should be clearly explained in simple local language. Detailed component analysis of these activities should be done to identify any deficiencies which can be remedied leading to better awareness activity achieving higher positive impact on the breast cancer awareness of women in the developing countries..

\section{Acknowledgements}

The authors acknowledge the director Dr Syed Waqar Hyder and his team at the Institute of Nuclear Medicine and Oncology Lahore (INMOL) and the pharmaceutical company (Sanofi-Aventis) for arranging the awareness seminar for women in Lahore, Pakistan. There were no grants or financial benefits and authors declare no competing interests.

\section{References}

AbdelHadi M S A (2006). Breast Cancer Awareness Campaign, Will it make a difference? J Family Commun Med, 13, 115-19.

Ahmed BA (2010). Awareness and practice of breast cancer and breast self examination among university students in Yemen. Asian Pac J Cancer Prev, 11, 101-5.

Ahmed F, Mahmud S, Hatcher J, Khan SM (2006) Breast cancer risk factor knowledge among nurses in teaching hospitals of Karachi, Pakistan: a cross sectional study. BMC Nurs, 5, 6.

Al-Shammari A, A Al-Dahlawi A, A Nurhussen A, et al ( 2012). Effectiveness of an innovative community-based breast cancer awareness workshop. BMC Proceedings, 6, 25.

Anderson BO, Shyyan R, Eniu Aet al., (2006) Breast Cancer in limited resource countries: An overview of the breast health Global Health Initiative guidelines 2005. Breast J, 12, 3-15. Austoker J, Bankhead C, Forbes LJL, et al (2009). Interventions 


\section{Samina Khokher et al}

to promote cancer awareness and early presentation: systemic review. Brit J Cancer, 101, 31-39.

Aziz Z, Sara S,Akram M, Saeed A(2004). Socioeconomic status and breast cancer survival in Pakistani women. J Pak Med Assoc, 54, 448-53.

Bhurgri Y, Bhurgri A, Nishter S, et al (2006). Pakistan - Country Profile of Cancer and Cancer Control 1995-2004.J Pak Med Assoc, 56, 124-30.

Burke W, Oslen AH, Pinsky LE, Reynolds SE,Press NA (2001). Misleading presentation of breast cancer in popular magazines. Eff Clin Pract, 4, 58-64.

Dolen NC, Lee AM, McDemott MM (1997). Age related differences in breast cancer related knowledge, beliefs and perceived risk among women visiting an academic general medicine practice. Cancer, 80, 413-20.

Gupta SK, Pal DK, Garg R, et al (2009). Impact of a Health Education Intervention Program Regarding Breast Self Examination by Women in a Semi-Urban Area of Madhya Pradesh, India. Asian Pac J Cancer Prev, 10, 1113-17.

Gürdal SÖ, Saraçoğlu GV, Oran EŞ, Yankol Y, Soybir GR. (2012). The effects of educational level on breast cancer awareness: a cross sectional study in Turkey. Asian Pac J Cancer Prev, 12, 295-300.

Hadi MA, Hassali MA, Shafie AA, Awaisu A (2010). Evaluation of breast cancer awareness among female university students in Malaysia. Pharmacy Practice (Internet), 8, 29-34.

Harirchi I, Azary S, Montazeri A et al (2012). Literacy and breast cancer prevention: a population-based study from Iran. Asian Pac J Cancer Prev, 13, 3927-30.

Hussain MM, Ansari AK, (1996), Late presentation of carcinoma breast in Pakistani women. Pak Armed Forces Med J, 46, 11-5.

Jaffary A, Mansuri F, Shamim S (2005). Knowledge attitudes and practices regarding breast cancer screening in women of various social strata. J Surg Pak, 10, 44-7.

Jemal A, Bray F, Melissa M et al (2011). Global cancer statistics. Ca Cancer J Clin, 61, 69-90.

Karayurt O, Özmen D, Çetinkaya AC. (2008). Awareness of breast cancer risk factors and practice of breast self examination among high school students in Turkey. BMC Public Health, 8, 359.

Khakbazan Z, Roudsari RB, Taghipour A, Mohammadi E, Pour RO (2014). Appraisal of Breast Cancer symptoms by Iranian women: Entangled cognitive, emotional and sociocultural responses. Asian Pac J Cancer Prev, 15, 8135-42.

Khokher S, Qureshi MU, Riaz M, Akhtar N, Saleem A (2012). Clinicopathologic profile of breast cancer patients in Pakistan: Ten years data of a local cancer hospital. Asian Pac J Cancer Prev, 13, 693-8.

Khokher S, Qureshi W, Mahmood S, et al (2011). Knowledge, Attitude and Preventive Practices of Women for Breast cancer in the Educational Institutions of Lahore, Pakistan. Asian Pac J Cancer Prev, 12, 2419-24.

Kumar S, Imam AM, Manzoor NF, et al (2009). Knowledge attitude and preventive practices for breast cancer among health care professionals at Agha Khan Hospital Karachi. JPMA, 59, 474-8.

Mena M, Wiafe-Addai B, Sauvaget C et al (2013). Evaluation of the impact of a breast cancer awareness program in rural Ghana: A cross-sectional survey. Int J Cancer.

Moore MA, AriyaratneY, Badar F, et al (2009). Cancer epidemiology in South Asia- Past, present and future. Asian Pac J Cancer Prev, 10, 49-67.

Naeem M, Khan N, Aman Z, et al (2008). Pattern of breast cancer experience at lady reading hospital, Peshawer. J Ayub Med Coll Abbottabad, 20, 22-5.

Odusanya OO, Tayo OO (2001) Breast cancer knowledge attitudes and practice among nurses in Lagos, Nigeria. Acta Oncol, 40, 844-8.

Okobia MN, Bunker CH, Okonofua FE, Osime U (2006). Knowledge, attitude and practice of Nigerian women towards breast cancer; a cross sectional study. World J Surg Oncol, 1, 4-11.

Parsa P, Kandiah M (2005). Breast cancer knowledge, perception and breast self examination practices among Iranian women. Int Med $J, 4,17-24$.

Parvez T, Anwar M (2005). Knowledge attitude and preventive practices for breast cancer. JCPSP, 11, 363-6.

Radi SM (2013). Breast cancer awareness among Saudi females in Jeddah. Asian Pac J Cancer Prev, 14, 4307-12.

Rahman JA (2003). Knowledge attitude and practice on breast cancer among female population of Alur Batu village, Kuantan and its related factors in June 2003. Singapore Med J, 10, 90-4.

Ranasinghe HM, Ranasinghe M, Rodrigo C, et al (2013). Awareness of breast cancer among adolescent girls in Colombo, Sri Lanka: a school based study. BMC Public Health, 13, 1209.

Saeed RS, Bakir YY, Ali LM (2014). Are women in Kuwait aware of Breast Cancer and its diagnosticprocedures? Asian Pac J Cancer Prev, 15, 6307-13.

Sathian B, Nagaraja SB, Banerjee I et al (2014). Awareness of breast cancer warning signs and screening methods among female residents of Pokhara valley, Nepal. Asian Pac J Cancer Prev, 15, 4723-6

Somdatta P, Baridalyne N (2008). Awareness of breast cancer in women of an urban resettlement colony. Indian J Cancer, 45, 149-53.

Wakefield MA, Loken B, Hornick RC (2010). Use of mass media campaigns to change health behaviour. Lancet, 376, 1261-71.

Yavari P, Pourhoseingholi MA (2007). Socioeconomic factors association with knowledge and practice of breast self examination. Asian Pac J Cancer Prev, 8, 618- 22. 